\title{
Estratégias de progressão temática com temas tópicos não marcados em artigos científicos da Engenharia Civil ${ }^{1}$
}

\author{
Thematic Progression Strategies with Unmarkded Topical \\ Theme in Civil Engineering Journal Articles
}

\author{
Cristiane Fuzer ${ }^{2 *}$ \\ Universidade Federal de Santa Maria \\ Santa Maria - Rio Grande do Sul / Brasil \\ Leila Bárbara ${ }^{3 * *}$ \\ Pontifícia Universidade Católica de São Paulo \\ São Paulo - São Paulo / Brasil
}

\section{Resumo}

Este trabalho analisa padrões de Tema na organização da informação, em língua portuguesa, como estratégias de progressão temática ao longo das seçôes de dez artigos de um corpus constituído por 95 artigos produzidos por pesquisadores experientes da Engenharia Civil. Com base na Linguística Sistêmico-Funcional (HALLIDAY, 1978, 2004; HALLIDAY \& MATTHIESSEN, 2004), a análise concentra-se no Tema tópico, como sugerido por Daneš (1974), para compreender o sistema de Tema nas seçōes dos artigos. A análise qualiquantitativa de realizações léxico-gramaticais da metafunção textual evidenciou a predominância de Temas tópicos não marcados, funcionando como diferentes estratégias de progressão temática ao longo dos textos.

\footnotetext{
* crisfuzer@yahoo.com.br

**1barbara@uol.com.br
} 


\section{Palavras-chave}

Gramática Sistêmico-Funcional; metafunção textual; Tema tópico; estratégias de progressão temática; artigo científico.

\section{Abstract}

This paper analyzes Theme patterns in the organization of information in Portuguese as strategies of thematic progression throughout the 10 journal articles of a corpus of 95 articles written by skilled Civil Engineer researchers. Based on Systemic Functional Linguistics (HALLIDAY, 1978, 2004; HALLIDAY \& MATTHIESSEN, 2004), the analysis focuses on the lexicogrammar realization of the topical Theme as suggested by Daneš (1974) to understand the system of the Theme in the articles sections. The qualitative and quantitative analysis of the lexicogrammatical realizations of the Theme highlighted the predominance of unmarked topical Themes which work as different thematic progression strategies throughout the texts.

\section{Keywords}

Systemic Functional Grammar; textual metafunction; topical Theme; thematic progression strategies; journal article. 


\section{INTRODUÇÃO}

$1 \begin{aligned} & \text { linguagem transforma experiências (próximas ou distantes da vida } \\ & \text { cotidiana) em significados. Com base nessa premissa entende-se que as } \\ & \text { teorias, incluindo-se as científicas, devem prever esse "poder semogênico }\end{aligned}$ da linguagem" (HALLIDAY, 2004, p. 3), ou seja, que a linguagem é um sistema que constrói significados ${ }^{4} \mathrm{e}$, portanto, não corresponde às experiências humanas nem as reflete ou descreve, mas sim as interpreta (HALLIDAY e MARTIN, 1993). Essa natureza da linguagem é demonstrada por uma teoria científica que seja "uma interpretação linguística da experiência" (HALLIDAY e MARTIN, 1993 , p. 8) e reconheça a função da gramática de transformar experiências em significados.

A evolução da ciência decorre da evolução do pensamento científico; sendo o pensamento construído na e por meio da linguagem, a "casa de força de uma língua é a sua gramática"5 (HALLIDAY e MARTIN, 1993, p. 12). Para descrever como os significados são produzidos pelas ciências, destacam-se as características léxico-gramaticais da escrita científica, em trabalhos como os de Halliday e Martin (1993), Halliday (2004), Martin e Veel (2005), tendo por base princípios da teoria sistêmico-funcional (HALLIDAY, 1978, 1994; HALLIDAY; HASAN, 1989).

Compartilhando essa perspectiva de linguagem, este trabalho focaliza, no contexto científico, as realizações léxico-gramaticais do sistema de Tema, que realiza a metafunção textual da linguagem, para entender os significados produzidos pelas escolhas temáticas do falante/escritor em diferentes textos e para entender como a organização das informações pode manter o ouvinte/leitor "ciente do caminho a ser percorrido" (OLIONI, 2010a, p. 42).

As investigações de Gosden (1993) e Mckenna (1997) sobre a relação entre a posição Sujeito gramatical e o Tema em artigos científicos e em relatórios técnicos de engenheiros mostram predominância de Temas não marcados. Martinez (2003) comparou os tipos de Tema usados na metodologia e na 
discussão de resultados em artigos científicos da Biologia; Ghadessy (1999), Ebrahimi e Khedri (2011) analisaram a estrutura temática em resumos de artigos de diferentes ciências.

Entre os estudos sobre aspectos linguísticos em artigos científicos em português, têm sido focalizadas características léxico-gramaticais em conclusões de artigos de Linguística e Odontologia (MORAIS, 2011) e processos verbais em artigos da Linguística Aplicada (VIVAN, 2010), Engenharia Civil (FUZER, 2012) e ciências diversas (BARBARA e MACÊDO, 2011). A estrutura temática é estudada em textos narrativos (OLIONI, 2010a) e de popularização da ciência (FUZER, 2002, 2006); porém, sobre a estrutura temática no discurso científico em português não foram encontradas investigações.

Este trabalho, com base na análise das realizações léxico-gramaticais do Tema em artigos científicos produzidos por pesquisadores experientes da área de Engenharia Civil, busca sistematizar padrões de funções discursivas do Tema em português como estratégias de progressão temática na organização das informações.

Para isso, parte-se de pressupostos sobre o sistema léxico-gramatical que realiza a metafunção textual da linguagem, conforme descrito por Halliday e Matthiessen (2004), Martin, Matthiessen e Painter (2010), Matthiessen (1995), com ênfase no componente Tema tópico, associado ao sistema de informação. Dessa forma, são revisados os padrões de organização das informações para a escrita científica em inglês propostos por Daneš (1974) e, com base na análise dos Temas tópicos em artigos científicos da Engenharia Civil em português, são descritos outros padrões como estratégias de progressão temática nesse tipo de texto.

\section{PRESSUPOSTOS TEÓRICOS}

Nesta seção, focaliza-se o sistema léxico-gramatical que realiza a metafunção textual (sistema de Tema), em associação com o sistema de informação, para, por último, revisar os padrões de progressão temática propostos por Daneš (1974).

\subsection{Sistema temático e sistema de informação}

Na Gramática Sistêmico-Funcional, o sistema temático situa-se no estrato léxico-gramatical da linguagem, e o sistema de informação, no estrato 
semântico, ambos realizados como som ou como escrita no estrato da fonologia/ grafologia, em determinado contexto de uso (FIG. 1).

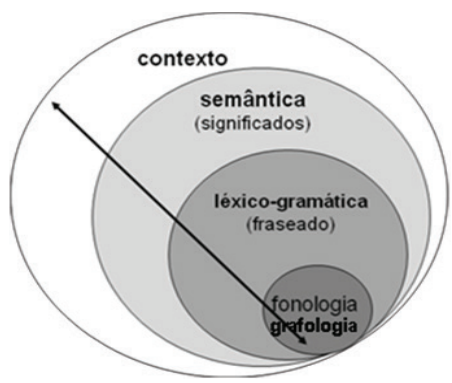

FIGURA 1 - Estratificação do sistema linguístico (adaptado de HALLIDAY e MATTHIESSEN, 2004, p. 25).

Olhar por meio do sistema é olhar para o registro, definido como "uma variedade funcional da linguagem, os padrões de instanciação do sistema associados a determinados tipos de contexto" (HALLIDAY e MATTHIESSEN, 2004, p. 27). Um registro pode ser representado como uma configuração particular de probabilidades sistêmicas, evidenciadas por análises quantitativas - realizadas, neste trabalho, para o levantamento de padrões com relação ao uso do Tema tópico em língua portuguesa.

O sistema temático se organiza em termos da apresentação de informação; no que diz respeito à informação, sistema paralelo a ele, o Tema tipicamente contém informação conhecida enquanto o Rema traz informação nova. Assim, Tema e Rema mostram o contexto local da oração com relação ao contexto geral do texto, evidenciando o ponto de partida em relação ao que veio antes, de modo a esclarecer como sua contribuição se encaixa no texto (MATTHIESSEN, 2005; MARTIN, MATTHIESSEN e PAINTER, 2010).

Nesse contexto local, ou ponto de partida, o conhecido, em termos de informação, o Tema, é o elemento proeminente da estrutura, enquanto o restante da mensagem, para onde a oração se move após o ponto de partida, é o Rema (HALLIDAY e MATTHIESSEN, 2004) que contém informação nova.

Um critério para a identificação dos limites do Tema em uma oração é: o Tema vai até o primeiro elemento que função no sistema transitividade, a saber, participante, processo ou circunstância (MARTIN, MATTHIESSEN e PAINTER, 2010). O Tema pode se constituir de um ou mais elementos das três 
metafunções, podendo ser, portanto, simples (constituído apenas de elemento com significado ideacional - o Tema tópico) ou múltiplo (constituído, além do Tema tópico, de elementos interpessoais e/ou textuais). Quando se constitui de elementos interpessoais, classifica-se como Tema interpessoal e, quando se constitui de elementos coesivos - sequenciais ou continuativos -, classifica-se como Tema textual (HALLIDAY e MATTHIESSEN, 2004).

O Tema tópico, foco do presente trabalho, será não marcado quando tiver função de Sujeito no sistema de MODO e, simultaneamente, função de participante no sistema de transitividade, e será marcado quando desempenhar outra função (Adjunto/Circunstância, Complemento/Participante ou Predicador/Processo). Em português, quando Sujeito, o Tema tópico pode estar ou não expresso linguisticamente; pode, portanto, quando elíptico, ser recuperado pelo processo de coesão textual (BARBARA e GOUVEIA, 2004). O Tema tópico pode se constituir por unidades maiores do que um nome, tais como grupos nominais que expandem o nome principal, mais de um grupo nominal ou grupos preposicionais ligados ao nome e oraçóes encaixadas ${ }^{6}$.

O Tema, como contexto local criado para a oração, é orientado para o discurso anterior (para o que o falante/escritor já disse); mais especificamente, dá ao falante/escritor "os recursos para direcionar a atenção do ouvinte/leitor para a parte da oração que é uma informação Nova” (MATTHIESSEN, 1995, p. 516). O mapeamento dos Temas ao longo de um texto relaciona-se com um sistema paralelo: o sistema de informação, constituído de informação Dada (o conhecimento partilhado com o falante/escritor) e informação Nova (ainda não conhecido pelo ouvinte/leitor).

Tipicamente, a informação Dada é apresentada pelo falante/escritor como recuperável pelo ouvinte/leitor no contexto, uma vez que já foi mencionada ou estará inserida no contexto de situação, sendo fequentemente expressa por pronomes que se referem aos interlocutores (contexto extralinguístico), elementos dêiticos e elementos mencionados previamente (contexto linguístico). Elementos anafóricos podem carregar foco de informação; quando contrastivos, caracterizam-se como Informação Nova (OLIONI, 2010b).

Junto à informação Dada aparece a informação Nova, que é o conhecimento a ser adquirido pelo ouvinte/leitor e apresentado pelo falante/ escritor. Não tendo sido mencionada anteriormente, a informação Nova não é recuperável pelo contexto, 
Assim, no nível da oração, o fluxo do discurso é gerenciado por meio da estrutura de Tema, que possibilita a coesão e a identificação de mecanismos utilizados na organização da mensagem, e da estrutura de informação, que possibilita o fluxo do discurso. Em ordem não marcada, estrutura temática e estrutura de informação coincidem. Entretanto, o falante/escritor pode optar por apresentar a informação Nova em posição temática e a informação Dada em posição de Rema, quando objetiva estabelecer contraste entre informações ou dar mais proeminência textual ao novo.

Em resumo, Tema e Rema são orientados com relação ao falante/ escritor, enquanto informação Dada e informação Nova são orientadas com relação ao ouvinte/leitor (OLIONI, 2010b), explicando por que, para Halliday e Matthiessen (2004), a organização temática das orações é o fator mais significativo no desenvolvimento do texto. Ao se observar como são mapeadas as escolhas temáticas ao longo das orações e dos complexos oracionais, é possível verificar, pela sucessão de Temas e pelo fluxo das informações ao longo do texto, o que tem sido chamado de "progressão temática".

\subsection{Estratégias de progressão temática}

Tendo por base a noção de estrutura temática determinada contextualmente, a tradição da Escola de Praga concebe progressão temática não pela ordem das palavras, mas pela conexão textual. Daneš (1974) considera que todas as orações num discurso são conectadas linguisticamente ao discurso precedente e propõe três tipos de progressão temática: constante, linear e Temas derivados.

A progressão temática constante consiste na manutenção do mesmo Tema ao longo de uma sequência de oraçôes. O Tema pode ser retomado por pronomes, sinônimos, repetição ou por elipse, permanecendo inalterado e se ligando a diferentes Remas.

A progressão temática linear consiste em apresentar como Tema um elemento introduzido no Rema de uma oração precedente, e assim sucessivamente.

Temas derivados ocorrem quando um item de um parágrafo ou seção origina subitem que funciona como Tema de outras oraçôes. Em outras palavras, um elemento do Tema ou do Rema deriva outros Temas.

Essa proposta de Daneš (1974) é incorporada por Fries (2009) à noção de Tema da teoria sistêmico-funcional proposta por Halliday (1978). Na 
proposta de Fries (2009), as diferentes maneiras de conectar os Temas de um texto estabelecem padrões que contribuem para a organização textual (OLIONI, 2010b).

Este trabalho, na perspectiva sistêmico-funcional, sistematiza os padrões de utilização do Tema tópico para explicar a organização das informações em artigos científicos em língua portuguesa. Os procedimentos metodológicos usados para viabilizar tal sistematização estão descritos na próxima seção.

\section{METODOLOGIA}

\subsection{Procedimentos de coleta e constituição do corpus para análise}

A coleta de textos para esta pesquisa selecionou artigos científicos disponíveis na plataforma www.scielo.com.br a partir das palavras "engenharia" e "concreto", com pelo menos um autor formado em Engenharia Civil (ou subáreas), conforme dados fornecidos no próprio artigo ou no currículo Lattes, resultando 95 textos.

Na sequência, converteram-se os arquivos para o formato .txt, procedendo-se à limpeza dos textos (apagamento de notas e cabeçalhos com repetição dos nomes dos autores e dados da revista, ou códigos que substituíam figuras e tabelas) e renomeando- se os arquivos com uma letra identificativa do gênero discursivo $(\mathrm{A}=$ artigo), outra da área científica (EC = Engenharia Civil) e um número sequencial. Portanto, cada texto é aqui referido como AEC1, AEC2, e assim por diante.

A pesquisa se realizou em duas etapas, descritas na subseção 3.2. Na primeira, com auxílio da ferramenta Concord do programa WordSmith Tools 5.0 (SCOTT, 2008), foram utilizados todos os textos do corpus, constituído de 389.123 ocorrências das quais 15.157 eram palavras distintas. A seguir, foram selecionados dez textos para análise pormenorizada, todos de Doutores em engenharia, professores em instituições de ensino superior, de acordo com seus currículos Lattes (CNPq).

\subsection{Procedimentos de análise}

A pesquisa se desenvolveu em duas etapas: 1) análise qualiquantitativa das realizações léxico-gramaticais do Tema e 2) sistematização de estratégias de progressão temática com Temas tópicos não marcados. 
Na primeira, foram realizados os seguintes procedimentos:

a) análise das funções léxico-gramaticais (nos sistemas de MODO e transitividade) dos elementos que constituem o Tema em 1.510 linhas de concordância no corpus;

b) verificação das frequências das realizações léxico-gramaticais do Tema tópico e sistematização de padrões de realização temática no corpus analisado.

Os resultados obtidos levaram à seleção aleatória de dez artigos que constituíram a amostra para análise manual das funções discursivas do Tema, com a adoção dos procedimentos a seguir:

a) análise dos Temas tópicos cuja realização léxico-gramatical manifestouse como mais frequente no corpus;

b) verificação da existência ou não de relação entre o Tema tópico da oração principal com as informações no Tema ou no Rema nas orações dos períodos, parágrafos ou seçōes anteriores do texto;

c) sistematização das ocorrências em categorias com base nas funções discursivas dos Temas tópicos na sequência de orações de cada texto, considerando-se a relação estabelecida com elementos em orações anteriores;

d) quantificação das ocorrências de cada categoria e levantamento dos padrões de organização textual no registro científico em língua portuguesa.

\section{ANÁLISE E DISCUSSÃO DOS RESULTADOS}

Nesta seção, apresentam-se, em primeiro lugar, os resultados da análise das funções léxico-gramaticais dos elementos do corpus em posição temática. $\mathrm{Na}$ sequência, analisam-se, na amostra de textos, os Temas tópicos de realização léxico-gramatical mais frequentes no corpus e, por fim, apresenta-se uma proposta de sistematização de estratégias de progressão temática com Tema tópico em registro científico da língua portuguesa.

\subsection{Realizações léxico-gramaticais do Tema tópico}

A análise quantitativa dos elementos léxico-gramaticais em posição temática (TAB. 1) nos períodos dos artigos analisados evidencia a predominância 
de Temas tópicos não marcados, realizados prioritariamente por grupos nominais com função de Participante no sistema de transitividade e de Sujeito no sistema de MODO, seguidos de Temas marcados com função de Adjunto/ Circunstância, ambos cobrindo a maioria das ocorrências (86,70\%), ficando as demais funçōes com 13,30\% do total.

TABELA 1

Funções e realizações léxico-gramaticais de Tema Tópico em artigos de Engenharia Civil

\begin{tabular}{l|l|l}
\hline $\begin{array}{l}\text { Funções léxico-gramaticais no } \\
\text { nível da oração }\end{array}$ & $\begin{array}{l}\text { Realizações gramaticais no nível } \\
\text { do grupo }\end{array}$ & Frequência \\
\hline $\begin{array}{l}\text { Sujeito / Participante (explícito } \\
\text { ou em elipse) }\end{array}$ & Grupo nominal & $56,40 \%$ \\
\hline Adjunto / Circunstância & $\begin{array}{l}\text { Grupo adverbial } \\
\text { Grupo preposicional }\end{array}$ & $30,30 \%$ \\
\hline $\begin{array}{l}\text { Predicador sem Finito / Processo } \\
\text { (sem marca de Participante) }\end{array}$ & $\begin{array}{l}\text { Grupo verbal } \\
\text { Grupo verbal + se }\end{array}$ & $8,70 \%$ \\
\hline $\begin{array}{l}\text { Predicador com Finito / Processo } \\
\text { com Participante Posposto }\end{array}$ & Grupo verbal & $3,80 \%$ \\
\hline Complemento / Participante & $\begin{array}{l}\text { Grupo nominal } \\
\text { Grupo preposicional }\end{array}$ & $0,70 \%$ \\
\hline Oração relacional & $\begin{array}{l}\text { Verbo SER + grupo nominal / } \\
\text { grupo preposicional }\end{array}$ & $0,05 \%$ \\
\hline $\begin{array}{l}\text { Predicador / Processo no modo } \\
\text { imperativo }\end{array}$ & Grupo verbal & $0,05 \%$ \\
\hline TOTAL & & $100 \%$ \\
\hline
\end{tabular}

Tais resultados se assemelham aos de Gosden (1993), na análise das orações principais de 36 artigos em inglês de diferentes áreas em periódicos internacionais, e aos de Mckenna (1997), na análise de três relatórios de Engenharia em inglês (TAB. 2). 
TABELA 2

Comparação entre resultados de estudos sobre ocorrências de Tema tópico em inglês e português

\begin{tabular}{|c|c|c|c|}
\cline { 2 - 4 } \multicolumn{1}{c|}{} & $\begin{array}{c}\text { Artigos científicos } \\
\text { em inglês } \\
\text { (GOSDEN, 1993) }\end{array}$ & $\begin{array}{c}\text { Relatórios de } \\
\text { Engenharia em inglês } \\
\text { (MCKENNA, 1997) }\end{array}$ & $\begin{array}{c}\text { Artigos científicos } \\
\text { de Engenharia } \\
\text { Civil em português } \\
\text { (neste trabalho) }\end{array}$ \\
\hline $\begin{array}{c}\text { Frequência de Temas } \\
\text { tópicos não marcados } \\
\text { (Sujeito/Participante) }\end{array}$ & $67,20 \%$ & $79,20 \%$ & $65,05 \%$ \\
\hline $\begin{array}{c}\text { Frequência de } \\
\text { Temas tópicos } \\
\text { marcados (Adjunto/ } \\
\text { Circunstância) }\end{array}$ & $32,30 \%$ & $18,30 \%$ & $34,95 \%$ \\
\hline
\end{tabular}

Os resultados dos três corpora estão na mesma direção, apesar da maior diferença entre os relatórios e os artigos. Quanto aos artigos nas duas línguas, a diferença é pequena e na mesma direção que os relatórios.

A próxima seção analisa os Temas tópicos não marcados mais frequentes no corpus, bem como a relação entre eles e a informação em cada período dos textos da amostra selecionada.

\subsection{Estratégias de progressão temática com Tema tópico não marcado}

Apresentar informação nova ou retomar informação dada anteriormente no texto (HALLIDAY, 1994; BLOOR e BLOOR, 1995; HALLIDAY e MATTHIESSEN, 2004; EGGINS, 2004; MARTIN, MATTHIESSEN e PAINTER, 2010) é função reconhecida na literatura como básica do Tema tópico. A tabela 3 contém os resultados qualiquantitativos das demais funções discursivas do Tema tópico no corpus de estudo. 
TABELA 3

Funçōes discursivas do Tema tópico não marcado das oraçôes principais no corpus

\begin{tabular}{|c|c|c|}
\hline Funções discursivas do Tema tópico no corpus & Ocorrências & Percentuais \\
\hline $\begin{array}{c}\text { 1. Estabelecer contraste entre informações } \\
\text { 2. Retomar informação do Rema de período próximo } \\
\text { ou distante }\end{array}$ & 169 & $26,32 \%$ \\
\hline $\begin{array}{c}\text { 3. Agregar informação nova a parte do Tema ou Rema } \\
\text { do período anterior }\end{array}$ & 117 & $18,22 \%$ \\
\hline $\begin{array}{c}\text { 4. Introduzir informações novas } \\
\text { ou distante }\end{array}$ & 104 & $16,20 \%$ \\
\hline 5. Retomar informação do Tema de período próximo & 76 & $11,84 \%$ \\
\hline $\begin{array}{c}\text { 6. Juntar informações de Tema ou Rema de período } \\
\text { anterior }\end{array}$ & 23 & $3,58 \%$ \\
\hline $\begin{array}{c}\text { Totais } \\
642\end{array}$ & $100 \%$ \\
\hline
\end{tabular}

\subsubsection{Estabelecer contraste entre informações}

A tabela 3 mostra estabelecer contraste entre informações (26,32\%) como a função mais frequente do Tema no corpus de estudo, seguida de retomar informação do Rema (23,84\%), o que pode ser explicado pelo tipo de texto, que é geralmente extenso e enfoca assunto específico.

Essa função está exemplificada nos excertos (1), (2) e (3), cada um ilustrando, respectivamente, estas situações: referência a estudos prévios, descrição de materiais e métodos de pesquisa e diferenciação de dados ou resultados de experimentos.

A tematização de fontes bibliográficas, destacada em (1), funciona como um recurso discursivo para citar estudos prévios com o mesmo objetivo de investigação.

(1) Estudos realizados pela Gerdau (2003) verificaram a viabilidade de reciclagem da carepa de aço em artefatos de cimento para calçamento, através da substituição da areia e brita por carepa, apontando, assim, para a possibilidade da obtenção de produtos com custo significativamente inferior aos existentes no mercado. Cunha et al. (2006) e Martins (2006) realizaram as caracterizações física, 
química e mineralógica da carepa de laminação, as quais permitiram investigar suas propriedades e potencialidades industriais. Al-Otaibi (2008) investigou a possibilidade de reciclar carepa de aço em materiais cimentícios como agregado miúdo, analisando ạgamașsạs de cimento Portland com teores de $0 \%, 20 \%, 40 \%, 50 \%, 70 \%$ e 100\%. [AEC02]

Note-se que o critério de ordenação desses Temas no texto é a ordem cronológica de publicação das pesquisas, partindo da mais antiga, sistema evidenciado pelas datas citadas (“2003”, “2006” e “2008”).

Já em (2) os Temas tópicos não marcados são relacionados de forma contrastiva na descrição dos materiais e métodos de pesquisa e podem constituir uma seção separada (geralmente intitulada "Materiais e métodos") ou estar diluídos em seções diversas.

(2) [...] Os valores de força, deformação e deslocamento foram gravados usando-se o sistema de aquisição ADS 2000 da Lynx.

Os valores de flechas teóricas imediatas foram calculados para as três diferentes lajes de acordo com as Equaçóes 2 e 3, conforme procedimentos descritos na NBR 6118 (ABNT, 2003b). [AEC93]

Os Temas das duas oraçôes ("valores de força, deformação e deslocamento" e "valores de flechas teóricas imediatas") introduzem complexos oracionais contrastivamente. A colocação desses Sujeitos/Participantes em posição temática é suficiente para representá-los como diferentes, sem a necessidade de conectores lógicos que explicitem tal relação.

A diferenciação de dados ou resultados de experimentos, em (3), é outra finalidade do uso de Temas com função contrastiva encontrada.

(3) O trecho ascendente do diagrama força e deslocamento a tração foi aproximado por uma função linear, como mostra a Equação (2). O trecho descendente ou pós-pico pode ser aproximado por duas funções que seguem um comportamento exponencial (Equação (3). ${ }^{1}$ [AEC19] 
A presença de antonímia, explicitada pelos itens lexicais "ascendente" e "descendente", reforça o contraste entre os resultados tematizados obtidos na pesquisa, evidenciando uma importante estratégia de progressão temática, não prevista na proposta de Daneš (1974).

Note-se que esses usos do Tema se enquadram na categoria estabelecimento de contraste entre informações, aqui proposta, e não na categoria "Tema constante" de Daneš (1974), pois, embora haja repetição de alguns elementos - como "valores" em (2) e "trecho" em (3) -, a informação retomada não é a mesma, haja vista a expansão desses grupos nominais. Em (2), o grupo nominal "valores" é expandido pelos sintagmas preposicionais "de força, deformação e deslocamento" e "de flechas teóricas imediatas"; em (3), o grupo nominal "trecho" é expandido por outros grupos nominais que têm valor classificatório: "ascendente" e "descendente". A tematização de elementos diferentes no início das orações permite acrescentar informações sobre o assunto, fazendo o texto progredir simultaneamente à organização das informações. $\mathrm{O}$ frequente uso desse recurso no corpus parece indicar a necessidade de diversas informações serem relacionadas ao longo do texto, característica de artigos científicos.

\subsubsection{Retomar informações presentes no Rema de período anterior}

A segunda função mais frequente do Tema tópico não marcado, apresentada na tabela 3, é retomar, total ou parcialmente, informações presentes no Rema de período anterior (23,84\%). Essa categoria se apresenta de duas maneiras distintas: retomar o Rema de período imediatamente anterior $(15,27 \%)$ e retomar o Rema de período distante $(8,57 \%)$.

A retomada de elementos do Rema de período imediatamente anterior converge com a estratégia de progressão temática "linear" de Daneš (1974) na organização textual dos artigos. Os excertos (4), (5) e (6) mostram o funcionamento dessa função discursiva do Tema (em negrito) que retoma elementos presentes no Rema (com destaque pontilhado) de oração anterior, contribuindo para a coesão e a progressão temática em três situações de transição: de uma oração ou complexo oracional para outro; de um parágrafo para outro e de uma seção para outra. 


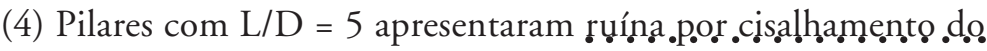

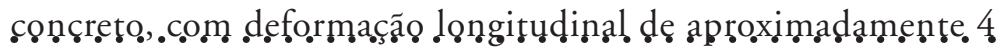
(FIG. 4a). Esse modo de ruína foi observado para todas as classes de resistência do concreto. [AEC04]

(5) [...] Devido ao formato tronco-cônico dos blocos, as amostras foram retificadas até atingir uma espessura uniforme. Foram ainda introduzidos entalhes na ạmoștrạ por onde o plano de ruptura deve ocorrer, a fim de criar uma superfície enfraquecida que permita o controle do ensaio.

A amostra era colada previamente sob uma base guia de aço, garantindo assim a ausência de erros de paralelismo entre a amostra e os pratos. [...] [AEC19]

(6) A investigação apresenta uma comparação dos resultados experimentais com outros dois trabalhos existentes na literatura (Takey, 2004 e Beltrão, 2003) e, também, com resultados teóricos, objetivando a validação dos resultados obtidos para o șisțẹ̣ạa eștrụtụurạl propososțọ.

2. Ensaios experimentais

O sistema estrutural analisado consistiu em uma laje de concreto com dois perfis metálicos e blocos de poliestireno expandido (EPS - isopor) preenchendo os espaços entre os perfis, conforme apresentado na FIG. 1(a). [AEC09]

Em (4), o pronome demonstrativo "Esse" presente no Tema "Esse modo de ruína” explicita a relação anafórica com o Rema da oração anterior. É tematizada a informação que foi apresentada como Nova no Rema da oração precedente, com as informações distribuídas no parágrafo progredindo com coesão.

Em (5), um elemento do Rema ("amostra") é tematizado na oração que inicia outro parágrafo na mesma seção. De maneira semelhante, em (6), parte do Rema ("o sistema estrutural proposto") que finaliza uma seção é retomada como Tema no parágrafo que dá início à seção seguinte.

A retomada do Rema de período distante, embora menos frequente que a categoria anterior, tem relevante contribuição na conexão de informações 
distribuídas em diferentes partes do texto, como exemplificam os excertos a seguir.

(7) 2. OBJETIVOS

[...] Nesse trabalho, o foco é a investigação do ẹfẹitọ.ḍẹ cọṇịnạmẹențọ nos pilares preenchidos de seção circular.

\section{ANÁLISE COMPARATIVA}

[...] Ambas as normas consideram o.efẹitọ dẹ .coṇinnạmẹnț̣.

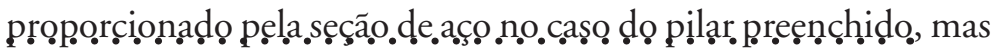
apenas o EC-4 apresenta uma formulação detalhada para estimar a contribuição de tạl .ẹẹiț̣.

No procedimento apresentado pelo EC-4, a redução da resistência do concreto pelo coeficiente 0,85 pode ser omitida para os pilares mistos preenchidos, já que a concretagem e o ensaio dos pilares ocorreram em um curto espaço de tempo (por volta de 28 dias) e os efeitos de retração e fluência não são expressivos e, além disso, trata-se de ensaios de curta duração. $\mathbf{O}$ efeito de confinamento é considerado quando a esbeltez relativa é menor que 0,5 e a excentricidade da força aplicada não ultrapassa $10 \%$ do diâmetro externo do tubo de aço. [AEC04]

No excerto (7), o termo "efeito de confinamento" aparece pela primeira vez em posição temática na seção de análise dos dados, tendo aparecido em seções anteriores do artigo, mas sempre integrando o Rema - inicialmente na seção de objetivos. Após o fornecimento, ao longo do texto, de informações que caracterizam esse termo técnico, na seção de Análise Comparativa essa informação passa a ser usada como um dado que, em posição temática, recebe maior proeminência na descrição de um procedimento. Temos, assim, um mecanismo para recuperar a informação apresentada no Rema em períodos distantes, em outro parágrafo ou seção, corroborando a progressão das informações ao reapresentar uma informação que se encontra em passagens distantes, possibilitando, assim, o estabelecimento de relações entre diversas unidades de informação distribuídas ao longo do texto.

O excerto (8) é outro exemplo que apresenta essa estratégia de tessitura de informação em nível macroestrutural. 
(8) 1. INTRODUÇÃO

[...]. Na análise realizada, o comportamento estrutural das lajes

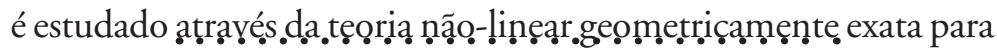
cascas inicialmente planas apresentada por Campello, Pimenta, e Wriggers (2003) em regime elástico não linear [...].

4. Plasticidade nas barras de aço

[...]. O vetor das tensóes pode ser utilizado para a definição da

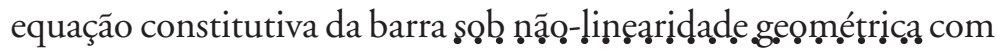
as deformaçoos extraídas diretamente do tensor E de Green (3).

5. CONCLUSÕES

$\mathrm{O}$ uso das teorias geometricamente exatas sob não-linearidade geométrica possibilitou a análise dos edifícios apresentados nesse trabalho [...]. [AEC12]

$\mathrm{Na}$ seção de Conclusão, o Tema tópico não marcado retoma uma informação utilizada como subsídio teórico em outras seções do artigo, nas quais aparece como parte do Rema. Assim, na Conclusão, as principais informações apresentadas como Novas, passíveis de explicação nas seções anteriores, sintetizam o que foi desenvolvido ao longo do artigo. Constata-se, portanto, que o uso de Tema tópico não marcado para recuperar informações do Rema de períodos distantes configura-se numa estratégia de progressão temática eficiente para textos longos com estrutura relativamente estável, como o artigo científico, justificando a presença dessa função com expressiva frequência nas seções dos artigos científicos analisados.

\subsubsection{Agregar informações novas a elementos recuperados do Tema ou do Rema de períodos anteriores}

$\mathrm{Na}$ terceira categoria apresentada na tabela 3, o Tema tópico não marcado agrega informações novas a elementos recuperados do Tema ou do Rema de períodos anteriores $(18,22 \%)$ e está relacionada com a noção de "junção semântica”, nos termos de Halliday (2004). Os excertos a seguir mostram diferentes situaçôes de retomada. 
(9) A. mạdẹiṛa desempenhou valor histórico no desenvolvimento da humanidade e, graças à proximidade das fontes desse material natural e a sua fácil trabalhabilidade é ainda amplamente utilizada nas construções rurais. A produção e o processamento de madeira de reflorestamento, tais como pinus e eucalipto, são atrativos para o setor do agronegócio. No âmbito das grandes construçôes, o eucalipto, mais recentemente, tem sido empregado em pontes e passarelas, como ilustrado por CALIL JÚNIOR et al. (2006). [AEC29]

Em (9), o ponto de partida da mensagem, no primeiro complexo oracional, é "A madeira", termo que é retomado, por repetição, no Tema tópico do segundo período: "A produção e o processamento de madeira de reflorestamento". A seu redor novos elementos são acrescentados: duas nominalizações ("produção" e "processamento"), representando operações de que a madeira é Meta (a estrutura congruente seria "madeira é produzida e processada”), e um grupo preposicional (“de reflorestamento"), que funciona como qualificador, representando uma classe (madeira de reflorestamento).

Lịẹ,.Chẹn,.W. e. .Chen. H...(2000). analisaram um edifício de 24 andares, mostrando a importância de combinar teorias de estabilidade com as teorias de plasticidade. $\mathbf{O}$ deslocamento lateral [[encontrado pelos autores citados] $]^{7}$ foi de $0,2195 \mathrm{~m}$ no topo do edifício, bastante próximo daquele encontrado por Fonseca Neto, (2005) de 0,2454 m, ao analisar o mesmo edifício com uma redução do núcleo. [AEC12]

Em (10), a expressão "pelos autores citados" integra o Tema tópico não marcado retomado por hiperonimia, "Liew, Chen, W. e Chen, H. (2000)", que, por sua vez, constitui o Tema da oração principal do complexo oracional antecedente. A esse constituinte é acrescentada informação nova realizada por um grupo nominal (“O deslocamento lateral”).

Os exemplos (9) e (10) mostram que o Tema tópico não marcado permite agregar informações novas a uma informação anteriormente tematizada. Já o excerto (11) evidencia que esse tipo de Tema também permite acrescentar informaçóes novas a um ou mais elementos do Rema do período precedente.

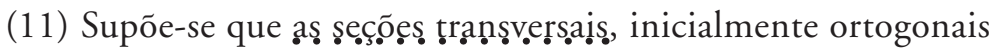
ao eixo da bạrṛą, permaneçam indeformáveis, porém deixam de 
ser ortogonais e planas, devido à consideração do empenamento por torção durante o seu movimento. Os pontos situados na seção transversal da barra sofrem um deslocamento e uma rotação; é superposto um deslocamento na direção ortogonal à seção transversal da barra na configuração deformada (FIG. 1). [AEC12]

Os termos "seção transversal" e "barra", já mencionados no Rema do primeiro período, são relacionados, de modo que o primeiro elemento expande, na forma de grupo preposicional ("da barra”), o segundo, que é reconstruído como Adjunto/Circunstância ("na seção transversal”). Ocorre, assim, uma junção semântica que constrói uma terceira "coisa", uma Circunstância que agrega nova informação: "os pontos" nela situados, sobre os quais o Rema subsequente se desdobra.

Por meio desses mecanismos gramaticais, o Tema tópico não marcado tem a função de retomar uma informação dada, presente no Tema ou no Rema de um complexo oracional anterior, e a ela acrescentar um elemento novo. Presente em todas as seções dos artigos analisados, esse recurso faz progredir o fluxo informacional do texto, possibilitando dar proeminência, simultaneamente, a um dado e a um novo inter-relacionados graças à propriedade de expansão dos grupos que desempenham a função de participantes da oração, conforme destaca Halliday (2004). Em vista disso, informação agregada pode ocorrer em qualquer parte do texto, exceto no início, em que é necessário apresentar informação nova.

\subsubsection{Introduzir informação nova}

A quarta função do Tema tópico não marcado no corpus, introduzir informação nova (16\%), foi encontrada principalmente nas seções de Introdução e Resultados em todos os artigos, apresentando informações novas importantes. No excerto (12), extraído do início de uma seção de Introdução, os Temas tópicos não marcados, em destaque, apresentam informações novas.

(12) A preocupação com a preservação do meio ambiente e aspectos vinculados à gestão ambiental é crescente nos últimos anos, apresentando-se como uma constante nos diversos segmentos industriais (Levy, 2001). [...]. 
A carepa de aço é um resíduo sólido gerado na fabricação do aço, produzida na oxidação da superfície do aço quando este se encontra em elevada temperatura [...]. [AEC02]

A informação tematizada na oração principal do primeiro complexo oracional ("A preocupação com a preservação do meio ambiente e aspectos vinculados à gestão ambiental") é retomada nos parágrafos seguintes, servindo para contextualizar o assunto. Apenas a informação nova, tematizada no segundo parágrafo - "A carepa de aço", que é o objeto da pesquisa - é retomada nas outras seçôes do artigo, para manter a unidade temática do texto.

No excerto (13), da Metodologia, o Tema tópico não marcado também é usado para apresentar novas informações, com "Concretos de classe C30, C60, C80 e C100" mencionados pela primeira vez no artigo, tematizando termos técnicos identificativos dos componentes utilizados para análise.

\subsection{CARACTERIZAÇÃO DOS COMPONENTES DA SEÇÃO MISTA}

Concretos de classe C30, C60, C80 e C100 foram usados para o preenchimento dos pilares de seção circular [...] [AEC04]

Temas tópicos não marcados também são bastante usados para apresentar informações novas na seção dos Resultados, principalmente na indicação de recursos auxiliares, como figuras, gráficos, quadros e tabelas, como em (14).

(14) [...] Considerando a influência da armadura de flexão, independente de sua tensão de escoamento, a atual versão da norma brasileira, a NBR 6118:2003, recomenda um perímetro de controle que acompanha as dimensões de pilares internos, ou seja, para uma laje com as mesmas características físicas e mecânicas, a tensão de cisalhamento será constante e a resistência da laje $(V R k=1,4 . V R d)$ será proporcional às dimensões dos pilares, conforme a equação 2 . A Figura 2 mostra o perímetro recomendado pela NBR 6118:2003. [AEC06]

Nesse excerto, o Tema "A Figura 2" anuncia o recurso visual que aparece na sequência do artigo, muito comum nas seções de análise dos resultados. 


\subsubsection{Retomar informação do Tema de período anterior}

A quinta categoria apresentada na tabela 3, denominada retomada de informações presentes no Tema de período anterior $(11,84 \%)$, apresenta-se de duas maneiras distintas: recuperar um Tema que ficou distante $(7,17 \%) \mathrm{e}$ recuperar o Tema do período imediatamente anterior $(4,67 \%)$.

A retomada de Tema que ficou distante possibilita, na configuração macroestrutural do artigo, recuperar informações já tematizadas em parágrafos da mesma seção, como em 15, ou de outras seções, como em 16.

\section{(15) 2.1 MODELO DE CARREGAMENTO I}

O primeiro modelo de carregamento considerado nessa investigação (Mello, 2005), (Mello et al.,2005), (Murray et al., 1997) é composto pela parcela estática correspondente ao peso do pedestre e uma combinação de harmônicos associados à excitação dinâmica. A força dinâmica que representa o caminhar humano é obtida através da equação (1). A força dinâmica que representa o caminhar humano é obtida através da equação (1). A Figura 1 apresenta uma função de carregamento dinâmico associada a uma caminhada com frequência do passo $\mathrm{fp}=1,856 \mathrm{~Hz}$. [...].

Esse modelo de carregamento objetiva simular, de maneira mais realista, a ação dinâmica gerada durante a caminhada. [...]. [AEC08]

Em (15), o Tema ("Esse modelo de carregamento"), que inicia o segundo parágrafo da seção teórica, mantém o foco da informação já tematizada no primeiro parágrafo, lexicalizando "o primeiro" por anáfora pronominal - "esse" na segunda menção. O exemplo (16) também mostra uma tendência de uso do Tema tópico não marcado para recuperar Temas que ficaram distantes.

\section{(16) INTRODUÇÃO}

[...] Os blocos de concreto vibro-compactados a seco em estruturas são normalmente produzidos por indústrias de préfabricação de concreto, conforme a NBR-6136 [15], e encontrados com diferentes geometrias e resistências à compressão. [...]

2 CARACTERIZAÇÃO FÍSICA DOS BLOCOS 
Os blocos de concreto adotados foram fornecidos pela empresa Presdouro e são unidades compostas por areia, cimento e agregado com dimensão máxima de 6,3 milímetros. [AEC19]

O Tema "Os blocos de concreto adotados", usado no início da segunda seção do artigo, recupera a informação do Tema "Os blocos de concreto vibrocompactados a seco em estruturas” da Introdução, em que, no Rema, são construídas representações que caracterizam de forma geral aqueles materiais. O Tema "Os blocos de concreto adotados" recupera, assim, todo o conjunto de informaçóes já fornecidas, mantendo o foco sobre os materiais definidos, que continuam sendo ponto de partida da mensagem. Vale mencionar que, em Remas posteriores, os blocos recebem outras representações mais específicas, particularizando os materiais usados na pesquisa realizada em foco no artigo.

Isso mostra que, num primeiro momento, a informação tematizada, geralmente um termo técnico, é definida ou caracterizada com base em trabalhos de outros autores, como "Mello (2005), Mello et al. (2005), Murray et al., (1997)", como em (15), ou em normas técnicas, como "NBR-6136", como em (16). Essa estratégia é usada para explicar o significado de palavras-chave do trabalho com base em fontes bibliográficas e, depois, recontextualizá-las no âmbito da pesquisa foco do artigo.

A segunda maneira de recuperação de informações tematizadas é retomar o Tema de períodos próximos, função a que Daneš (1974) denomina "Tema constante". Essa função tem um papel importante principalmente nas seções de desenvolvimento dos artigos analisados, como nos exemplos (17) e (18).

(17) $\mathrm{O}$ concreto armado oferece uma grande versatilidade para se moldar as diversas formas arquitetônicas, conforme CARVALHO \& FIGUEIREDO FILHO (2004); porém, [o concreto armado] apresenta um elevado peso específico e uma alta condutividade térmica, principalmente, se comparado às espécies de madeira de baixa densidade. Quando não pré-fabricado, em geral, ele requer um grande consumo de fôrmas e escoras. [O concreto armado] É um pseudo-sólido sujeito às diversas ações patológicas extrínsecas e intrínsecas (SOUZA \& RIPPER, 2004). [AEC29] 
Sendo o mesmo na sequência de orações, o Tema, indicado no início de (17), pode ficar em elipse, uma vez que a omissão do Sujeito é preferida à sua repetição, mantendo-se o ponto de partida da mensagem e preservando o fluxo informacional ao se acrescentar apenas a informação nova no Rema das orações da sequência. Nessa categoria, também é comum o emprego de pronomes demonstrativos para estabelecer relação anafórica, como ocorre em (18), em que "Essa armadura" retoma "A armadura de pele utilizada na laje mista", Tema da oração principal do período anterior.

(18) A armadura de pele utilizada na laje mista, para evitar fissurações na superfície, foi confeccionada com vergalhōes de bitola $6,3 \mathrm{~mm}$ dispostos a cada $200 \mathrm{~mm}$ na largura e no comprimento. Essa armadura foi disposta a, aproximadamente, $25 \mathrm{~mm}$ da face da mesa superior do perfil metálico. [AEC09]

A retomada de um mesmo Tema é mais utilizada nas seções de desenvolvimento dos artigos analisados, nas quais conhecimentos vão sendo revisados ou construídos com base nos conceitos enfocados. Assim, ocorrências desse recurso são raras na seção de Introdução, onde são mais comuns Temas que apresentam informações Novas ou agregam informaçôes Novas a Dados retomados. São raras também na Conclusão, onde são mais comuns Temas que retomam Temas ou Remas que ficaram distantes.

\subsubsection{Juntar informações de Tema ou Rema de período anterior}

Apesar de menos frequente no corpus (3,58\%), a junção de informações diferentes presentes no Tema ou no Rema de um ou mais períodos anteriores parece, em vista de sua complexidade relacional, característica da escrita elaborada (BERNSTEIN ([1990]2003) ${ }^{8}$ e é aqui exemplificada no excerto (19).

\section{(19) INTRODUÇÃO}

As pontes podem ser definidas como obras de arte destinadas à transposição de obstáculos naturais ou não, visando à locomoção de veículos diversos e pedestres com segurança e conforto. Nas estradas vicinais, essas obras são de fundamental importância para integração regional e, do ponto de vista do setor do agronegócio, 
para proporcionar condições para o tráfego de caminhões e máquinas durante a safra, bem como no escoamento final da produção agrícola.

Grande parte das pontes de estradas vicinais é executada em madeira e, embora tais estruturas representem baixo custo de execução, [tais estruturas] podem, conforme Mascia \& Soriano (2004), apresentar uma pequena durabilidade e um baixo desempenho estrutural. [AEC29]

No segundo parágrafo de (19), os elementos que constituem o Tema tópico da primeira oração ("Grande parte das pontes de estradas vicinais") corresponde a elementos que constituem Temas de orações anteriores: "pontes", na oração principal do primeiro complexo oracional, e "estradas vicinais", do segundo. A junção desses dois elementos forma o terceiro Tema, iniciando o parágrafo seguinte. Esse exemplo demonstra o poder semogênico dos grupos nominais que, conforme Halliday (2004), é dado pela capacidade de expansão para formas mais ou menos indefinidas. Assim, um nome pode ser expandido por grupos preposicionais ${ }^{9}$, como em (19), em que o grupo nominal "pontes" é expandido pelo grupo preposicional "de estradas vicinais", delimitando o contexto do estudo, ou seja, outros tipos de estradas estão excluídos da informação relativa ao elevado número de pontes construídas em madeira.

A informação que segue no Rema ("é executada em madeira") não se refere, portanto, às pontes em geral, mas a um tipo específico ("pontes de estradas vicinais"). O texto ainda progride na oração seguinte, em que o Tema passa a ser "essas estruturas", que, por sua vez, retoma a informação Dada, parte presente no Tema da primeira oração ("pontes de estradas vicinais" e parte presente no Rema da segunda oração ("em madeira"). Assim, deve-se interpretar que não são todas as pontes de estradas vicinais que podem "apresentar uma pequena durabilidade e um baixo desempenho estrutural", mas especificamente as pontes de estradas vicinais executadas em madeira.

Essa estrutura temática, assim como as demais analisadas neste trabalho (sistematizadas na Figura 2), parece acionar mecanismos típicos da escrita de código elaborado, o qual, de acordo com Bernstein (2003[1990], p. 82), regula "uma gama maior de possibilidades combinatórias do que os códigos restritos" Como a atenção do leitor/ouvinte não é considerada garantida, uma vez que o escritor/falante está se dirigindo a um público estranho, códigos elaborados 
precisam ser explícitos e apresentar alto grau de planejamento. Dessa forma, como salienta Soares (2003, p. 41), eles "constroem seus significados por meio de princípios mais gerais, que são acessíveis apenas a certos grupos" - neste caso, aos especialistas da área de Engenharia.

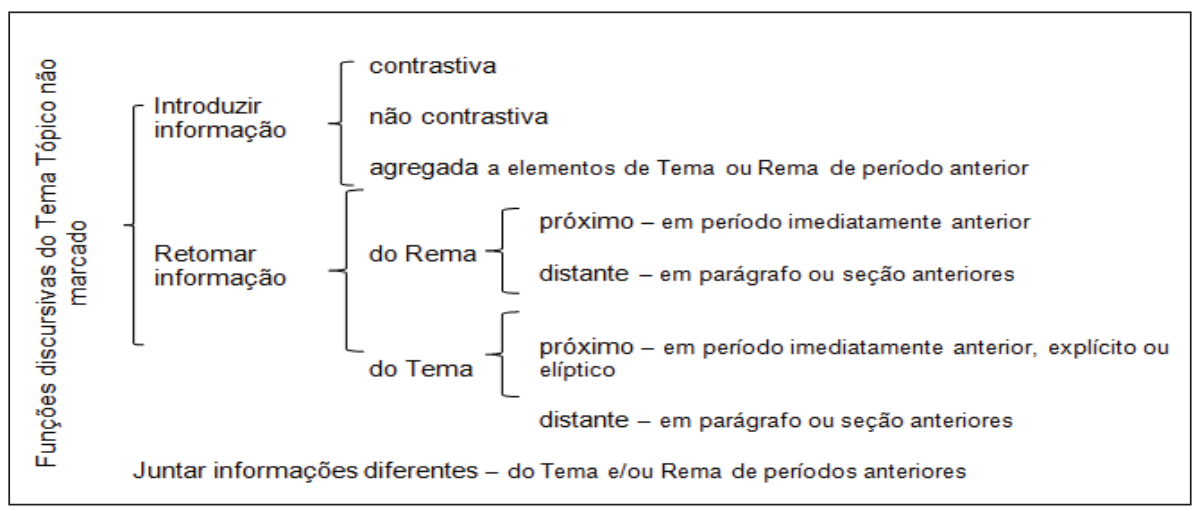

FIGURA 2 - Tipologia das funções discursivas do Tema tópico não marcado como estratégias de progressão temática em artigos científicos.

\section{CONSIDERAÇÕES FINAIS}

Esta análise de artigos científicos da Engenharia Civil, demostrando a predominância de Temas tópicos não marcados (realizados por grupos nominais com função de Sujeito/Participante) e Temas tópicos marcados (realizados por Adjuntos/ Circunstâncias) pode corresponder a um traço do registro científico, assim como demonstrado por Gosden (1993) e Mckenna (1997). Estudos em corpora em língua portuguesa de outras áreas do conhecimento poderão demonstrar se essa configuração léxico-gramatical do Tema tópico também se verifica em textos de outras ciências.

Ficou evidente que o Tema tópico não marcado é usado com funções discursivas variadas, sugerindo que estabelecer contraste entre informaçōes, retomar informações do Rema de períodos anteriores e agregar informação nova a parte do Tema ou Rema do período anterior são funções caracterizadoras da organização de informações, especialmente, nas seções de Introdução, Metodologia e Resultados.

O Tema tópico não marcado é usado para retomar (total ou parcialmente) informações que se encontram tanto no Rema de período imediatamente anterior, como no Rema de períodos mais distantes - geralmente em outro parágrafo ou seção. Corrobora a progressão das informaçôes ao apresentar como 
Dado uma informação apresentada como Nova em três ou quatro períodos ou até mesmo parágrafos anteriores, possibilitando o estabelecimento de relações entre diversas unidades de informação e contribuindo para a transição de informações em todas as seçôes dos artigos.

Retomar o mesmo Tema em período distante (geralmente em outro parágrafo ou seção) ou imediatamente anterior, estratégia que Daneš (1974) denomina "Tema constante", são as funções discursivas do Tema tópico não marcado mais frequentes nas seções em que são apresentados dados teóricos e análises dos resultados. Também nessas seçōes, o Tema é usado para juntar informaçōes diferentes presentes no Tema ou no Rema de períodos anteriores, apresentando maior complexidade relacional em termos de organização de informações na escrita científica.

Com base nesses resultados, pode-se levantar a hipótese de que as funções discursivas do Tema tópico não marcado encontradas nesta amostra de artigos de Engenharia Civil podem ser encontradas em artigos ou outros tipos de textos nesta e em outras áreas da ciência (como resumos, resenhas, ensaios, dissertações e teses) ou outros tipos de textos argumentativos ou, ainda, de outros contextos (escolar, político, jornalístico, jurídico, religioso, etc.), fornecendo subsídios importantes para o ensino de escrita acadêmica. A partir disso, pode-se delinear uma rede de sistemas das opções temáticas para "distinguir a escrita bem-sucedida da escrita sem sucesso", como propõe Berry (1995, p. xiv), em contextos mais variados de escrita planejada para tipos específicos de comunicação planejada.

\section{NOTAS}

${ }^{1}$ Pesquisa de Pós-Doutorado desenvolvida no Programa de Pós-Graduação em Linguística Aplicada e Estudos da Linguagem na PUCSP. Agradecemos as sugestôes de colegas do Grupo "Sistêmica Através das Línguas" (SAL), Adail Sebastião Rodrigues Jr., Célia Macêdo, Norma Joseph, Raymundo Olioni e Sara Cabral. Agradecemos também aos estudantes de Letras da UFSM Cristiane Gonçalves e Lucas Saldanha da Cruz a colaboração na coleta do corpus e no levantamento quantitativo dos dados. A responsabilidade pelo conteúdo do texto é nossa.

${ }^{2}$ Doutora, Professora Adjunta do Departamento de Letras Vernáculas e do Programa de Pós-graduação em Letras, UFSM. 
${ }^{3}$ Doutora, Professora Titular, Departamento de Linguística e Programa de PósGraduação em Linguística Aplicada, PUCSP.

${ }^{4}$ Semogênese é termo usado por Halliday (2003, p. 248) para se referir à propriedade pela qual a linguagem é concebida como "um sistema de fazer significado" (a meaningmaking system).

${ }^{5}$ As traduções foram realizadas pelas autoras deste trabalho.

${ }^{6}$ Orações encaixadas "funcionam dentro da estrutura de um grupo nominal, como orações relativas definidas” (HALLIDAY e MATTHIESSEN, 2004, p. 100).

${ }^{7}$ Os colchetes delimitam a oração encaixada.

${ }^{8}$ Apesar de duramente criticado, o que é comum no caso de inovadores controversos, Bernstein desenvolveu os conceitos de código elaborado e código restrito, para referirse à distinção entre falares altamente escolarizados e falares das classes populares que não tinham acesso às chamadas Public Schools da Inglaterra, frequentadas pelas elites. Essa distinção causou grandes reações, mas acabou sendo reconhecida com importante distinção sociolinguística, influenciando fortemente a área.

9 Importantes recursos gramaticais para especificar os objetos de estudo e delimitar o contexto em que tais objetos são investigados (HALLIDAY, 2004). Grupos nominais podem ser expandidos por grupos preposicionais e por orações encaixadas, que produzem um efeito de restrição (HALLIDAY e MATTHIESSEN, 2004).

10 Para o autor, as variantes restritas "são dependentes do contexto, dão origem a ordens particularistas de significado, onde os princípios são verbalmente implícita ou simplesmente anunciadas", ao passo que as variantes elaboradas são "independentes de contexto, dão origem a ordens universalistas de significado, onde os princípios são verbalmente explícitos" (BERNSTEIN, 2003[1971], p. 12).

\section{REFERÊNCIAS}

BARBARA, L.; GOUVEIA, C.A.M. It is not there, but [it] is cohesive: the case of pronominal ellipsis of subject in Portuguese. In: BANKS, D. (ed.). Text and texture: systemic functional viewpoints on the nature and structure of text. Paris: L'Harmattan, 2004. p. 159-172.

BARBARA, L;: MACEDO, C. M. M. Processosverbais em artigos acadêmicos: padrões de realização da mensagem. In: BARBARA, L.; MOYANO, E. Textos em linguagem acadêmica: exploraçōes sistêmico-funcionais em espanhol e português. Campinas, SP: Mercado das Letras, 2011. p. 213-231.

BERRY, M. Thematic options and success in writing (revised). In: GHADESSY, M. (Ed.). Thematic development in English texts. London and New York: Pinter, 1995. p. 55-84.

BERNSTEIN, B. Class, codes and control: The Structuring of Pedagogic Discourse. v. 4, London and New York: Routledge, 2003[1990]. 
. Class, codes and control: Theoretical Studies towards a Sociology of Language. v. 1, London and New York: Routledge, 2003[1971].

BLOOR, T.; BLOOR, M. The Functional Analysis of English: a Hallidayan Approach. London: Edward Arnold, 1995.

DANEŠ, F. Papers on Functional Sentence Perspective. The Hague: Mouton, 1974. p. 106-128.

EBRAHIMI, S.F.; KHEDRI, M. Thematicity in Research Article Abstracts: A cross Disciplinary Study. Educational Quest, International Journal of Education and Applied Science, v. 2, n. 3, p. 1-6, 2011.

EGGINS, S. An Introduction to Systemic Functional Linguistics. London: Pinter, 1994.

FRIES, P.H. The textual metafunction as a site for a discussion of the goals of linguistics and techniques of linguistic analysis. In: FOREY, G.; THOMPSON, G. Text type and Texture. London: Equinox, 2009. p. 8-44.

FUZER, C. Realização de processos verbais em artigos científicos da área de Engenharia Civil. DELTA, v. 28, n. esp., p. 473-494, 2012.

. Estratégias de progressão temática. In: MOTTA-ROTH, D.; BARROS, N.C.A.; RICHTER, M.G. Linguagem, cultura e sociedade. Santa Maria: PPGL, UFSM, 2006. p. 89-99. As regularidades e as possibilidades de progressão temática nos textos de popularização cientifica. Santa Maria: UFSM, 2002. 125 fl. Dissertação (Mestrado em Letras), Programa de Pós-Graduação em Letras, Universidade Federal de Santa Maria, Santa Maria, 2002.

GHADESSY, M. Thematic organization in academic articles abstracts. Estudios Ingleses de la Universidad Complutense, v. 7, p. 141-161, 1999.

GOSDEN, H. Discourse functions of subject in scientific research articles. Applied Linguistics, v. 14, n. 1, p. 56-75, 1993.

HALLIDAY, M.A.K. The Language of Science. Collected Works of M. A. K. Halliday, edited by Jonathan J. Webster, v. 5, London: Continuum, 2004.

On Language and On Linguistics. Collected Works of M. A. K. Halliday, edited by Jonathan J. Webster, v. 3, London: Continuum, 2003.

. An Introduction to Functional Grammar. $2^{\text {nd }}$ ed. London: Arnold, 1994.

; MARTIN, J. R. Writing Science: Literacy and Discursive Power. Pittsburgh: University of Pittsburgh Press, 1993.

; MATTHIESSEN, C.M.I.M. An Introduction to Functional Grammar. $3^{\text {nd }} \mathrm{ed}$. London: Arnold, 2004. 
; HASAN, R. Language, context, and text: aspects of language in a social-semiotic perspective. $2^{\text {nd }}$ ed. Oxford: Oxford University Press, 1989.

. Language as social semiotic. The social interpretation of language and meaning. London: Arnold, 1978.

MARTIN, J.R; MATTHIESSEN, C.M.I.M; PAINTER, C. Deploying functional grammar. Beijing: The Commercial Press, 2010.

MARTIN, J.R.; VEEL, R. Reading Science: critical and functional perspectives on discourses of science. London and New York: Routledge, 2005.

MARTINEZ, I.A. Aspects of theme in the method and discussion sections of biology journal article in English. Journal of English for Academic Purpose, v. 2, p. 103-123, 2003.

MATTHIESSEN, C. Lexicogrammatical Cartography: English Systems. Tokyo: International Language Sciences Publishers, 1995.

McKENNA, B. How Engineers Write: An Empirical Study of Engineering Report Writing. Applied Linguistics, v. 18, n. 2, p. 189-211, 1997.

MORAIS, F.B.C. Análise comparativa das conclusões de artigos científicos das áreas de Odontologia e Linguística. In: BARBARA, L.; MOYANO, E. Textos em linguagem acadêmica: explorações sistêmico-funcionais em espanhol e português. Campinas, SP: Mercado das Letras, 2011. p.193-212.

OLIONI, R.C. Tema e N-Rema: a construção do fluxo da informação. In: TAGLIANI, D. C. (Org.) Linguística e Língua Portuguesa: reflexões. Curitiba: CRV, 2010a. p. 69-86.

- Tema e N-Rema: a construção do fluxo de informação em textos narrativos sob uma perspectiva sistêmico-funcional. Porto Alegre: PUCRS, 2010. 196 fl. Tese (Doutorado em Letras), Programa de Pós-Graduação em Linguística Aplicada, Pontifícia Universidade Católica do Rio Grande do Sul, Porto Alegre, 2010b.

SCOTT, M. WordSmith Tools version 5, Liverpool: Lexical Analysis Software, 2008.

SOARES, L. L.C.P.S. Bernstein e o campo educacional: relevância, influências e incompreensões. Cadernos de Pesquisa, n. 120, p. 15-49, nov. 2003.

VIVAN, E.G.S. (2010). Principais usos de processos verbais e metáforas interpessoais em artigos de Linguística Aplicada. São Paulo: PUCSP, 208 fl. Tese (Doutorado em Linguística Aplicada e Estudos da Linguagem), Pontifícia Universidade Católica de São Paulo, São Paulo.

Submissão do artigo: 20/09/2013

Aprovação do artigo: 08/11/2103 
